\title{
H. pylori attenuates TNBS-induced colitis via increasing mucosal Th2 cells in mice
}

\author{
Yi-Zhong Wu ${ }^{1,2, *}$, Gao Tan ${ }^{1, *}$, Fang $\mathbf{W u}^{3}$ and Fa-Chao Zhi ${ }^{1}$ \\ ${ }^{1}$ Guangdong Provincial Key Laboratory of Gastroenterology, Department of Gastroenterology, Nanfang Hospital, Southern \\ Medical University, Guangzhou, China \\ ${ }^{2}$ Department of Gastroenterology, Hunan Provincial People's Hospital, Changsha, China \\ ${ }^{3}$ Department of Gastroenterology, The First Affiliated Hospital of Wenzhou Medical University, Wenzhou, China \\ *These authors contributed equally to this work
}

Correspondence to: Fa-Chao Zhi, email: zhifc41532@163.com

Gao Tan, email: tgao0316@163.com

Keywords: H. pylori, Crohn's disease, mucosal immunology, Th cells

Received: September 26, $2016 \quad$ Accepted: April 19, $2017 \quad$ Published: May 18, 2017

Copyright: Wu et al. This is an open-access article distributed under the terms of the Creative Commons Attribution License 3.0 (CC BY 3.0), which permits unrestricted use, distribution, and reproduction in any medium, provided the original author and source are credited.

\section{ABSTRACT}

There is an epidemiological inverse relationship between Helicobacter pylori (H. pylori) infection and Crohn's disease (CD). However, whether $H$. pylori plays a protective role against $C D$ remains unclear. Since 2, 4, 6-trinitrobenzene sulfonic acid (TNBS)-induced colitis is thought to resemble CD, we investigated whether $H$. pylori can attenuate TNBS-induced colitis in mice. Here we show that $H$. pylori can attenuate the severity of TNBS-induced colitis. In addition, $H$. pylori not only down-regulates Th17 and Th1 cytokine expression, but can up-regulate Th2 cytokine expression and increase the Th2:Th17 ratio of $\mathrm{CD4}^{+} \mathrm{T}$ in the colonic mucosa of TNBS-induced colitis. Our results indicate that $\boldsymbol{H}$. pylori attenuates TNBS-induced colitis mainly through increasing Th2 cells in murine colonic mucosa. Our finding offers a novel view on the role of $\boldsymbol{H}$. pylori in regulating gastrointestinal immunity, and may open a new avenue for development of therapeutic strategies in CD by making use of asymptomatic H. pylori colonization.

\section{INTRODUCTION}

Crohn's disease (CD), one type of inflammatory bowel disease (IBD) [1], is a life-long, chronic and relapsing disease that may occur anywhere in the gastrointestinal tract [2,3]. Although its pathogenesis is still poorly understood, genetic predisposition and environment, most notably the gut microorganism were thought to be the important aetiology [4]. However, up to now there is no decisive evidence of an etiologic role for any specific microbe. Whether there is a still unidentified specific microbe implicated in the pathogenesis of $C D$ deserves to be explored.

Helicobacter pylori (H. pylori), a highly adaptive gram-negative bacterium colonized the human gastric mucosa, has co-existed with humans for over 50,000 years $[5,6]$. Although it is positively correlated with the pathogenesis of gastric ulcers, gastric cancers and mucosa- associated lymphoid tissue lymphoma, less than $15 \%$ and $1 \%$ of infected patients will develop gastric ulcer and cancer, respectively $[7,8]$. Interestingly, $H$. pylori was recently isolated and detected in the intestinal mucosa of patients with CD [9]. Additionally, many recent studies have reported that $\mathrm{CD}$ patients have lower prevalence of $H$. pylori infection [10-12]. Furthermore, some reports have shown that there are rapid and clinical onset of CD after eradication of $H$. pylori infection $[13,14]$. Although these researches found an inverse relationship between $H$. pylori infection and $\mathrm{CD}$, whether $H$. pylori plays a protective role against $\mathrm{CD}$ and the potential protective mechanism remain unclear.

The purpose of this study was to determine whether H. pylori plays a protective role against $\mathrm{CD}$ and the potential protective mechanism. For this purpose, we used a murine model of CD-like colitis induced by 2 , 4, 6-trinitrobenzene sulfonic acid (TNBS) as described previously [15]. 


\section{RESULTS}

\section{Administration of $\boldsymbol{H}$. pylori attenuates the severity of TNBS-induced colitis}

In order to determine whether $H$. pylori attenuates the severity of TNBS-induced colitis, we treated mice with NCTC11639 (one H. pylori strain) after administration of TNBS enema and compared the disease activity scores, the colonic weight changes and the macroscopic and microscopic appearances of colons between mice treated with TNBS plus NCTC11639 and mice treated with TNBS only. We found that after administration of NCTC11639 enema, the TNBS-treated mice displayed less weight loss, less bleeding, greater stool consistency and low disease activity scores and had decreased colonic:body weight (Figure 1).

Consistent with the weight changes in the H. pyloritreated mice, we found that the TNBS-treated mice displayed less thickened edematous colonic walls and less mucosal ulcerations after administration of NCTC11639 enema, especially at distal $4-6 \mathrm{~cm}$ from the anus (Figure 2). In line with the macroscopic appearances of colons, we found that the mice treated with TNBS+NCTC11639 had less histological scores and displayed alleviated degree of inflammation of the colonic walls compared with the mice treated with TNBS only (Figure 3). Together, these results confirm that administration of $H$. pylori can attenuate the severity of TNBS-induced colitis.
Administration of $\boldsymbol{H}$. pylori down-regulates Th17 and Th1 cytokine expression, but up-regulates Th2 cytokine expression in murine colonic mucosa

Since abnormal T helper (Th) lymphocyte responses have been considered to play critical roles in the pathogenesis of IBD, we subsequently investigated whether H. pylori attenuates the severity of TNBS-induced colitis through regulating the Th lymphocyte responses. To test this, we treated mice with NCTC11639 after administration of TNBS enema and compared the colonic mRNA expression of multiple inflammation-mediating cytokines involved in Th17, Th1 and Th2 immune responses between mice treated with TNBS plus NCTC11639 and mice treated with TNBS only. We found that the colonic mRNA expression of Th17-related cytokines (IL-23p19, IL-17A, IL-6, IL-1 $\beta$, TGF- $\beta$ and STAT-3) was significantly lower in the mice treated with TNBS+NCTC11639 than in the mice treated with TNBS only (Table 1). Similarly, the colonic mRNA expression of Th1-related cytokines (IL-12p35, TNF- $\alpha$, IFN- $\gamma$ and STAT- 1 ) was significantly lower in the mice treated with TNBS+NCTC11639 than in the mice treated with TNBS only (Table 1). However, the changes of Th1-related cytokines were far weaker than the changes of Th17-related cytokines.

Interestingly, we found that the colonic mRNA expression of Th2-related cytokines (IL-4, IL-5, IL-10 and STAT-6) was significantly higher in the mice treated with
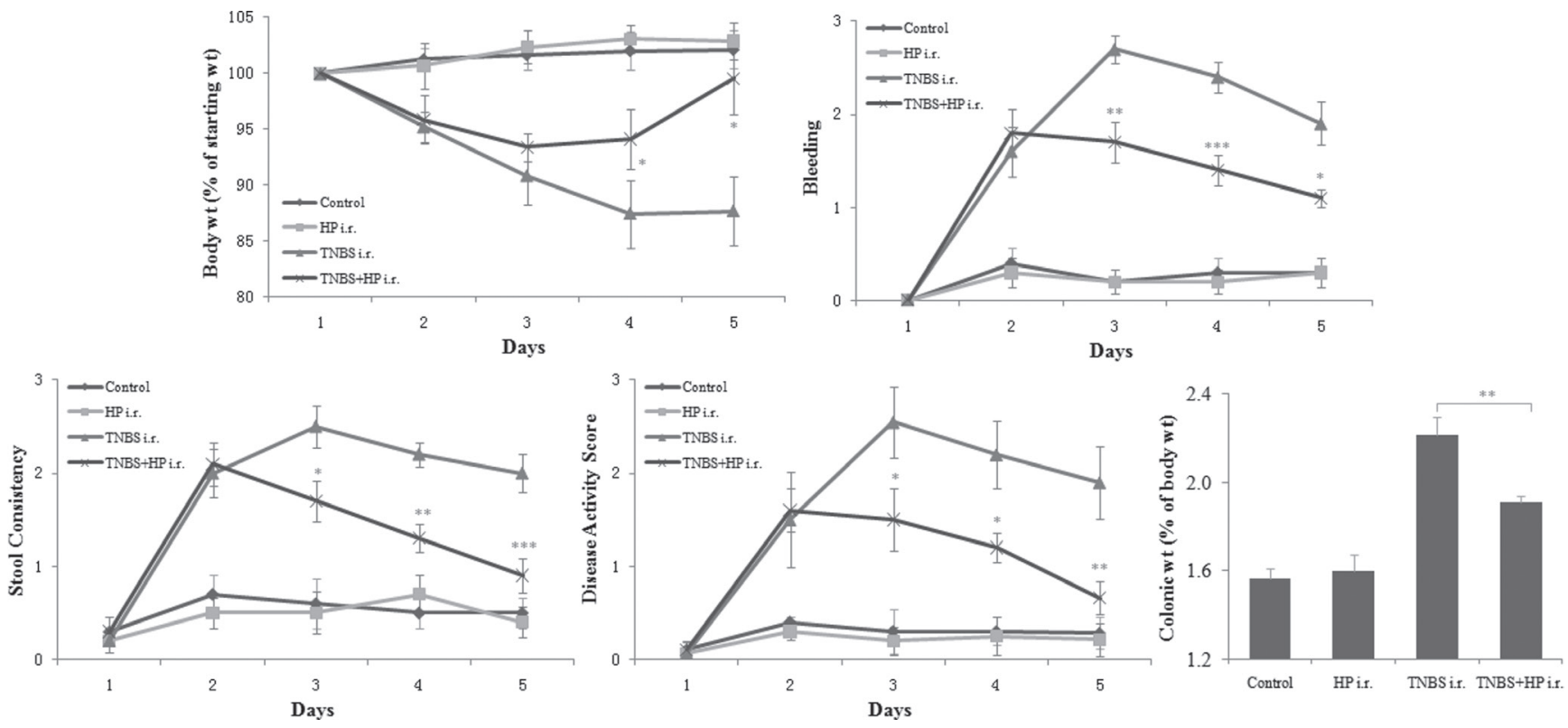

Figure 1: Mice receiving intrarectal (i.r.) administration of NCTC11639 displayed less weight loss, less bleeding, greater stool consistency and low disease activity scores and had decreased colonic:body weight. Mice were treated with $2.5 \%$ TNBS (day 1 ) with and without NCTC11639 (days 2-4) via an i.r. route in TNBS+ NCTC11639 and TNBS groups, respectively. Mice were treated with saline as control. Data are shown as the mean \pm SD from 10 mice per group. $* P<0.05, * * P<0.01, * * * P<0.001$ vs TNBS groups. 
Table 1: Th-related gene expression in mouse colonic mucosa detected by real-time PCR

\begin{tabular}{ccccc}
\hline Gene & Control & NCTC11639 & TNBS & TNBS+NCTC11639 \\
\hline IL-12p35 & $1 \pm 0.06$ & $0.90 \pm 0.06$ & $1.35 \pm 0.06$ & $0.63 \pm 0.08^{*}$ \\
TNF- $\alpha$ & $1 \pm 0.06$ & $0.93 \pm 0.14$ & $2.76 \pm 0.44$ & $1.23 \pm 0.10^{*}$ \\
IFN- $\gamma$ & $1 \pm 0.08$ & $0.91 \pm 0.08$ & $1.59 \pm 0.01$ & $0.32 \pm 0.01^{* *}$ \\
STAT-1 & $1 \pm 0.01$ & $0.97 \pm 0.01$ & $2.26 \pm 0.04$ & $1.44 \pm 0.02^{* *}$ \\
IL-23p19 & $1 \pm 0.34$ & $1.10 \pm 0.26$ & $2.16 \pm 0.01$ & $1.81 \pm 0.01^{* *}$ \\
IL-17A & $1 \pm 0.15$ & $1.22 \pm 0.24$ & $5.15 \pm 0.22$ & $1.11 \pm 0.03^{*}$ \\
IL-6 & $1 \pm 0.25$ & $0.89 \pm 0.35$ & $5.79 \pm 0.54$ & $0.61 \pm 0.02^{*}$ \\
IL-1 $\beta$ & $1 \pm 0.52$ & $0.85 \pm 0.14$ & $30.27 \pm 10.66$ & $0.86 \pm 0.19^{*}$ \\
TGF- $\beta$ & $1 \pm 0.06$ & $1.21 \pm 0.09$ & $1.82 \pm 0.15$ & $1.21 \pm 0.15^{*}$ \\
STAT-3 & $1 \pm 0.03$ & $0.93 \pm 0.05$ & $3.47 \pm 0.12$ & $0.67 \pm 0.08^{* *}$ \\
IL-4 & $1 \pm 0.02$ & $1.96 \pm 0.03$ & $0.25 \pm 0.03$ & $4.71 \pm 0.20^{*}$ \\
IL-5 & $1 \pm 0.03$ & $1.57 \pm 0.04$ & $0.27 \pm 0.04$ & $0.85 \pm 0.01^{*}$ \\
IL-10 & $1 \pm 0.20$ & $1.17 \pm 0.20$ & $0.32 \pm 0.03$ & $0.82 \pm 0.01^{* *}$ \\
STAT-6 & $1 \pm 0.08$ & $1.21 \pm 0.08$ & $0.18 \pm 0.01$ & $0.26 \pm 0.02^{*}$ \\
\hline
\end{tabular}

Relative mRNA levels are normalized to $\beta$-actin and expressed as a fold relative to the Control groups. Data are shown as the mean \pm SD from 10 mice per group. ${ }^{*} P<0.05,{ }^{* *} P<0.01$ vs TNBS groups.

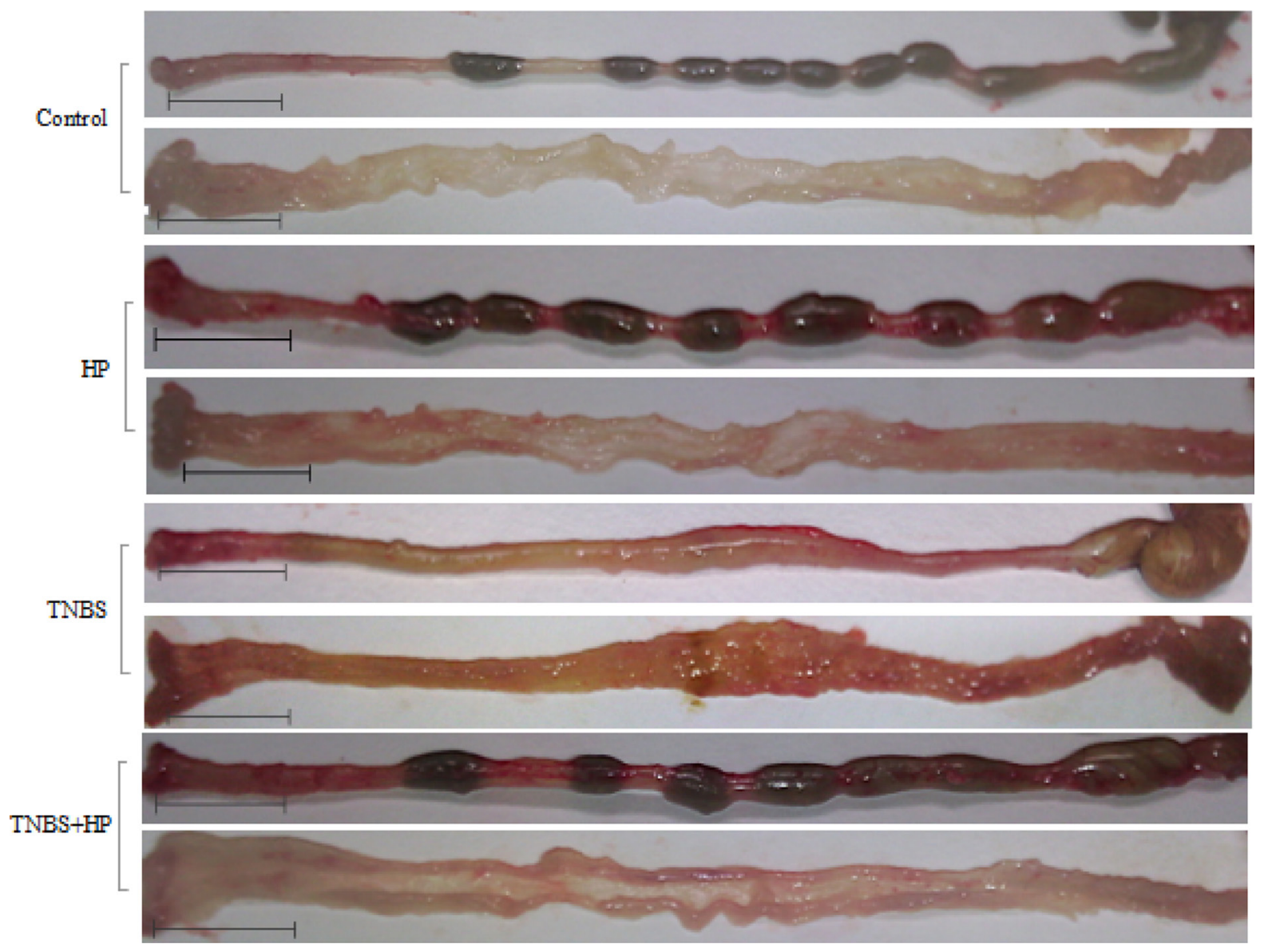

Figure 2: Macroscopic appearance of colons from Control (saline-treated mice), HP-treated mice, TNBS-treated mice and TNBS + NCTC11639-treated mice. TNBS-treated colons display thickened edematous walls and mucosal ulcerations, especially at distal 4-6 cm from the anus, while these changes are ameliorated in TNBS + NCTC11639-treated mice. Bars represent $1 \mathrm{~cm}$. 
TNBS+NCTC11639 than in the mice treated with TNBS only (Table 1). Together, these results provide evidence that $H$. pylori can attenuate the severity of TNBS-induced colitis mainly through regulating the Th17 and Th2 lymphocyte responses.

\section{Administration of $\boldsymbol{H}$. pylori increases the Th2: Th17 ratio of $\mathrm{CD4}^{+} \mathrm{T}$ in murine colonic mucosa}

To further elucidate the potential mechanism by which $H$. pylori attenuates the severity of TNBSinduced colitis, we treated mice with NCTC11639 after administration of TNBS enema, then isolated $\mathrm{CD}^{+} \mathrm{T}$ in murine colonic mucosa and finally determined the levels of Th17 and Th2 cells by FCM. We found that the mice treated with TNBS+NCTC11639 had decreased levels of Th17 cells, increased levels of Th2 cells and increased Th2: Th17 ratio of $\mathrm{CD}^{+} \mathrm{T}$ in colonic mucosa compared with the mice treated with TNBS only (Figure 4). These results suggest that $H$. pylori might inhibit and promote the differentiation of Th17 and Th2 to attenuate the severity of TNBS-induced colitis, respectively.

\section{DISCUSSION}

This study is focused on exploring whether $H$. pylori plays a protective role against $\mathrm{CD}$ and the potential protective mechanism. Our results in a murine model of TNBS-induced CD-like colitis show that $H$. pylori enema plays a protective role against $\mathrm{CD}$. We found that $H$. pylori enema can attenuate the severity of TNBS-induced colitis from the macroscopic and microscopic appearances of murine colons.

In further experiments concerning the protective mechanism by which $H$. pylori plays a protective role against $\mathrm{CD}$, our data show that $H$. pylori enema can regulate the Th17, Th1 and Th2 lymphocyte responses to attenuate the severity of TNBS-induced colitis. We found that $H$. pylori not only down-regulated the Th17 cytokine expression and to a lesser extent, the Th1 cytokine expression, but also up-regulated Th2 cytokine expression in murine colonic mucosa. Moreover, H. pylori can increase the Th2:Th17 ratio of $\mathrm{CD}^{+} \mathrm{T}$ in murine colonic mucosa. These findings suggest that $H$. pylori might inhibit and promote the differentiation of Th17 and Th2 to attenuate the severity of TNBS-induced colitis, respectively.

Recent studies found that abnormal Th17 responses have vital roles in the pathogenesis of many chronic inflammatory diseases, including CD [16-19]. As the advances in understanding the function of Th17 cells, the Th1/Th2 paradigm has now been replaced by the new Th1/Th2/Th17 paradigm. Here we found that $H$. pylori can down-regulate Th17 profile and Th1 profile, but upregulate Th2 profile. In addition, some studies found that the Th2 profile may be important in balancing the immune

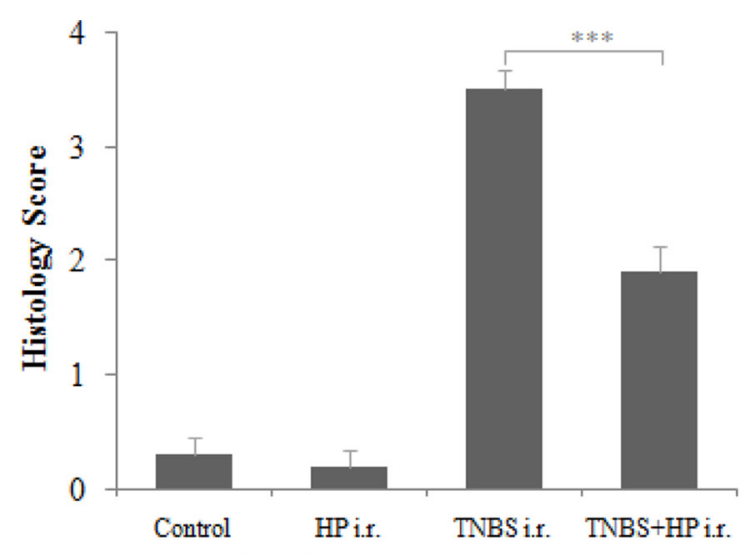

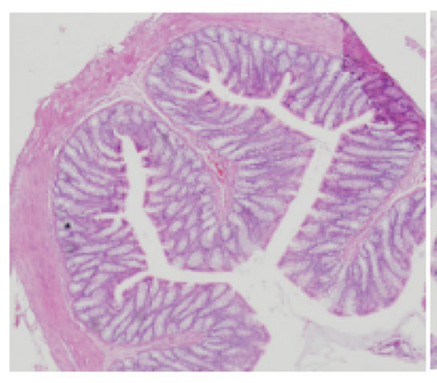

Control

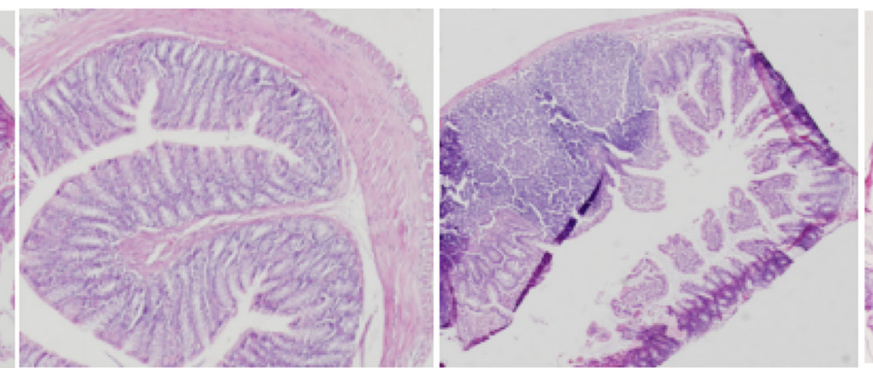

TNBS i.r.

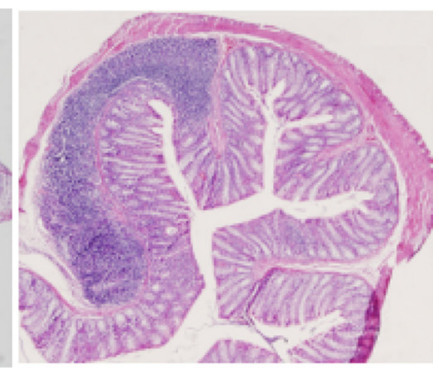

TNBS+HP i.r.

Figure 3: Microscopic appearance of colons from Control, HP-treated mice, TNBS-treated mice and TNBS + NCTC11639treated mice. Paraffin-embedded sections of the distal 4-6 cm from the anus were stained with HE. A, no significant inflammation in the bowel wall. B, severe transmural inflammation in the bowel wall. C, moderate inflammation in the bowel wall. All sections are shown at $100 \times$ magnification. 
response $[14,20]$. Therefore, it is feasible that $H$. pylori offers protective roles against $\mathrm{CD}$ by increasing $\mathrm{Th} 2$ profile to balance Th1/Th2/Th17 cell responses.

In summary, this is the first study to demonstrate that $H$. pylori attenuates TNBS-induced colitis mainly through increasing the Th2 cells in murine colonic mucosa. This finding is significant because it not only can offers a novel view on the role of $H$. pylori in regulating gastrointestinal immunity, but also may open a new avenue for development of therapeutic strategies in $\mathrm{CD}$ by making use of asymptomatic $H$. pylori colonization.

\section{MATERIALS AND METHODS}

\section{Animals}

Male BALB/c mice aged 6-8 weeks were purchased from the Department of Laboratory Animal Center of Southern Medical University, housed and fed in the animal maintenance facility at Southern Medical University. All animal experiments were reviewed and approved by the Experimental Animal Care and Ethical Committee at Nanfang Hospital of Southern Medical University.

\section{Bacterial enema preparation}

$H$ pylori (NCTC11639 strain) obtained from Guangdong Provincial Key Laboratory of Gastroenterology of Nanfang Hospital were inoculated on Campylobacter- selective agar (BD Biosciences) supplemented with $5 \%$ sterile horse blood, $5 \mu \mathrm{g} / \mathrm{ml}$ rimethoprim, $10 \mu \mathrm{g} / \mathrm{ml}$ vancomycin and $10 \mu \mathrm{g} / \mathrm{ml}$ nystatin, and cultured at $37^{\circ} \mathrm{C}$ in a humidified microaerophilic atmosphere with $5 \% \mathrm{O}_{2}$, $10 \% \mathrm{CO}_{2}$ and $85 \% \mathrm{~N}_{2}$. After 2 days, the bacteria was resuspended and diluted with sterile $0.9 \%$ saline solution. The bacterial concentration was estimated by using a spectrophotometer $\left(1 \mathrm{OD}_{600}=1 \times 10^{9} \mathrm{CFU} / \mathrm{ml}\right)$. The H pylori suspension at the concentration of $1 \times 10^{9} \mathrm{CFU} /$ $\mathrm{ml}$ was used as the bacterial enema.

\section{Animal studies}

The experimental schedule is outlined in Supplementary Figure 1. For model 1, TNBS-induced colitis studies were performed as per the protocol described previously [15]. For model 2, these studies were performed as the model-1experiment, but $500 \mu \mathrm{l}$ of $H$ pylori enema was administrated into the mouse colonic lumen continuous 3 days after administration of $100 \mu \mathrm{l}$ of TNBS solution. For models 3 and 4, these control studies only used saline and HP enemas, respectively. All harvested mice of models 1, 2, 3 and 4 were sacrificed and subsequently, their colons were intactly removed. The colons were longitudinally opened, cleaned and weighted after their length was measured. Since the distal $4-6 \mathrm{~cm}$ of the TNBS-treated colons were remarkably thickened and edematous, paraffin sections and total RNA isolation were taken from these regions. Paraffin sections were prepared
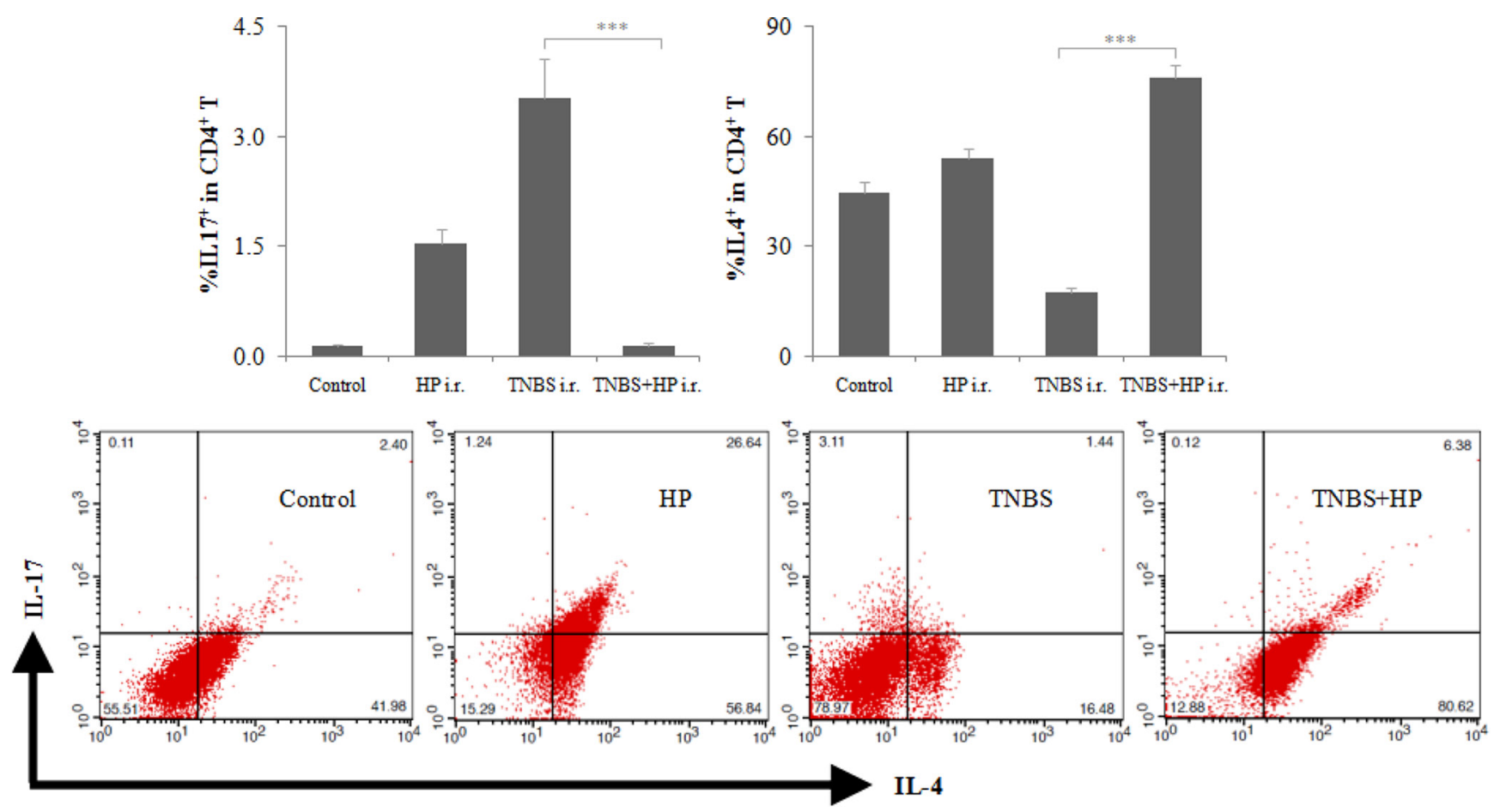

Figure 4: Intrarectal (i.r.) administration of NCTC11639 increases the Th2:Th17 ratio of CD4 ${ }^{+}$T in murine colonic mucosa. Mice were first treated with saline (Control), HP, TNBS or TNBS+NCTC11639, then isolated CD4 ${ }^{+}$T in murine colonic mucosa and finally determined the levels of Th17 and Th2 cells by FCM. Upper, percentage of IL-17 ${ }^{+}$and IL- $4^{+}$cells in CD4 ${ }^{+}$T cells. Bottom, representative plots. Data are shown as the mean \pm SD from 10 mice per group. $* * * P<0.001$ vs TNBS groups. 
for H\&E to assess the degree of inflammation graded semiquantitatively from 0 to 4 as previously described [21].

\section{Clinical assessment}

Body weight (\% starting weight), bleeding and stool consistency were measured as clinical parameters to calculate a disease activity score. The scoring for three parameters were as follows: $\%$ starting weight $(0=>99 \%$, $1=90-99 \%, 2=85-90 \%, 3=<85 \%$ ); bleeding $(0=$ negative, $1=$ faint blue on hemoccult, $2=$ blue on hemoccult, $3=$ gross red); stool consistency $(0=$ normal, 1 = slightly soft, $2=$ loose, $3=$ liquid). The average of three clinical parameters was used as the disease activity score.

\section{Real-time PCR}

Total RNA was isolated from fresh colonic tissue using the RNAiso Plus (Takara Bio) and then cDNA synthesis was performed using the PrimeScript RT reagent Kit with gDNA Eraser (Takara Bio). Real-time PCR was performed in triplicate using the LightCycler 480 System (Roche). Each 20- $\mu \mathrm{l}$ PCR reaction contained $5 \mu \mathrm{l}$ cDNA corresponding to $25 \mathrm{ng}$ RNA as a template, $0.5 \mu \mathrm{M}$ of each primer (Supplementary Table 1), and $1 \times$ LightCycler 480 SYBR Green I Master (Roche). Samples were loaded into the LightCycler 480 Multiwell Plate 96 (Roche) and incubated for initial denaturation at $95^{\circ} \mathrm{C}$ for $10 \mathrm{~min}$ followed by 45 cycles, each cycle consisting of $95^{\circ} \mathrm{C}$ for $15 \mathrm{~s}$, "touchdown" of $-1^{\circ} \mathrm{C} /$ cycle from the start annealing temperature $65^{\circ} \mathrm{C}$ to the end $60^{\circ} \mathrm{C}$ for $5 \mathrm{~s}$, and $72^{\circ} \mathrm{C}$ for $10 \mathrm{~s}$. $\beta$-actin was used an internal standard, and $\Delta \Delta \mathrm{CT}$ values were calculated to obtain fold changes relative to the control group.

\section{Cell isolation and flow cytometry}

Lamina propria lymphocytes were isolated from fresh colonic tissue as described previously [22] and the $\mathrm{CD}^{+} \mathrm{T}$ cell population was obtained from these lymphocytes by positive selection by mouse $\mathrm{CD} 4^{+} \mathrm{T}$ cell isolation columns as the manufacturer's protocol (Miltenyi Biotec). After that, these $\mathrm{CD} 4^{+} \mathrm{T}$ cells were incubated with $10 \mu \mathrm{g} / \mathrm{ml} \mathrm{BFA,} 50 \mathrm{ng} / \mathrm{ml}$ PMA and $750 \mathrm{ng} / \mathrm{ml}$ Ionomycin (Sigma) at $37^{\circ} \mathrm{C}$ in a tissue culture incubator. Four hours later, surface and intracellular cytokine staining was performed as described previously [22]. FITC antimouse IL-17A and PE anti-mouse IL-4 were purchased from BioLegend. Finally, flow cytometry was performed on FACSCalibur (BD Biosciences) and analyzed using FlowJo software (Tree Star Inc.).

\section{Statistical analysis}

The results are shown as the mean \pm standard deviation. Statistical significance was determined by oneway analysis of variance with Tukey's multiple comparisons under equal variances or with Dunnett T3's multiple comparisons under unequal variances. a value of $P<0.05$ was considered to be statistically significant.

\section{Authors' contributions}

F.Z. and G.T. conceived and designed the studies. Y.W. and G.T. performed the experiments. G.T. wrote the manuscript and prepared the table and figures. F.Z., G.T., Y.W. and F.W. reviewed the manuscript.

\section{ACKNOWLEDGMENTS AND FUNDING}

This work was supported by the National Natural Science Foundation of China (No. 81170341, No. 81370502 and No. 81402037), and supported by Natural Science Foundation of Zhejiang Province (LY15H030015).

\section{CONFLICTS OF INTEREST}

The authors declare no competing financial interests.

\section{REFERENCES}

1. Podolsky DK. Inflammatory bowel disease. N Engl J Med. 2002; 347:417-429.

2. Tan G, Li RH, Li C, Wu F, Zhao XM, Ma JY, Lei S, Zhang WD, Zhi FC. Down-regulation of human enteric antimicrobial peptides by NOD2 during differentiation of the paneth cell lineage. Sci Rep. 2015; 5:8383.

3. Lawrance IC, Wu F, Leite AZ, Willis J, West GA, Fiocchi C, Chakravarti S. A murine model of chronic inflammationinduced intestinal fibrosis down-regulated by antisense NF-kappa B. Gastroenterology. 2003; 125:1750-1761.

4. Kaser A, Zeissig S, Blumberg RS. Inflammatory bowel disease. Annu Rev Immunol. 2010; 28:573-621.

5. Linz B, Balloux F, Moodley Y, Manica A, Liu H, Roumagnac P, Falush D, Stamer C, Prugnolle F, van der Merwe SW, Yamaoka Y, Graham DY, Perez-Trallero E, et al. An African origin for the intimate association between humans and Helicobacter pylori. Nature. 2007; 445:915-918.

6. Falush D, Wirth T, Linz B, Pritchard JK, Stephens M, Kidd M, Blaser MJ, Graham DY, Vacher S, Perez-Perez GI, Yamaoka Y, Megraud F, Otto K, et al. Traces of human migrations in Helicobacter pylori populations. Science. 2003; 299:1582-1585.

7. Luther J, Owyang SY, Takeuchi T, Cole TS, Zhang M, Liu M, Erb-Downward J, Rubenstein JH, Chen CC, Pierzchala AV, Paul JA, Kao JY. Helicobacter pylori DNA decreases pro-inflammatory cytokine production by dendritic cells and attenuates dextran sodium sulphateinduced colitis. Gut. 2011; 60:1479-1486.

8. Dorer MS, Talarico S, Salama NR. Helicobacter pylori's unconventional role in health and disease. PLoS Pathog. 2009; 5:e1000544. 
9. Oliveira AG, Rocha GA, Rocha AM, Sanna M, Moura SB, Dani R, Marinho FP, Moreira LS, Ferrari ML, Castro LP, Queiroz DM. Isolation of Helicobacter pylori from the intestinal mucosa of patients with Crohn's disease. Helicobacter. 2006; 11:2-9.

10. Xiang Z, Chen YP, Ye YF, Ma KF, Chen SH, Zheng L, Yang YD, Jin X. Helicobacter pylori and Crohn's disease: a retrospective single-center study from China. World $\mathrm{J}$ Gastroenterol. 2013; 19:4576-4581.

11. Sonnenberg A, Genta RM. Low prevalence of Helicobacter pylori infection among patients with inflammatory bowel disease. Aliment Pharmacol Ther. 2012; 35:469-476.

12. Papamichael K, Konstantopoulos P, Mantzaris GJ. Helicobacter pylori infection and inflammatory bowel disease: is there a link? World J Gastroenterol. 2014; 20:6374-6385.

13. Jovanovic IR, Milosavjevic TN, Jankovic GP, Micev MM, Dugalic PD, Saranovic D, Ugljesic MM, Popovic DV, Bulajic MM. Clinical onset of the Crohn's disease after eradication therapy of Helicobacter pylori infection. Does Helicobacter pylori infection interact with natural history of inflammatory bowel diseases? Med Sci Monit. 2001; 7:137-141.

14. Tursi A. Onset of Crohn's disease after Helicobacter pylori eradication. Inflamm Bowel Dis. 2006; 12:1008-1009.

15. Wirtz S, Neufert C, Weigmann B, Neurath MF. Chemically induced mouse models of intestinal inflammation. Nat Protoc. 2007; 2:541-546.
16. Geremia A, Biancheri P, Allan P, Corazza GR, Di Sabatino A. Innate and adaptive immunity in inflammatory bowel disease. Autoimmun Rev. 2014; 13:3-10.

17. Di Sabatino A, Biancheri P, Rovedatti L, MacDonald TT, Corazza GR. New pathogenic paradigms in inflammatory bowel disease. Inflamm Bowel Dis. 2012; 18:368-371.

18. Kayama H, Nishimura J, Takeda K. Regulation of intestinal homeostasis by innate immune cells. Immune Netw. 2013; 13:227-234.

19. McGovern D, Powrie F. The IL23 axis plays a key role in the pathogenesis of IBD. Gut. 2007; 56:1333-1336.

20. Hruby Z, Myszka-Bijak K, Gosciniak G, Blaszczuk J,Czyz W, Kowalski P, Falkiewicz K, Szymanska G, Przondo-Mordarska A. Helicobacter pylori in kidney allograft recipients: high prevalence of colonization and low incidence of active inflammatory lesions. Nephron. 1997; 75:25-29.

21. Fuss IJ, Boirivant M, Lacy B, Strober W. The interrelated roles of TGF-beta and IL-10 in the regulation of experimental colitis. J Immunol. 2002; 168:900-908.

22. Ivanov, II, McKenzie BS, Zhou L, Tadokoro CE, Lepelley A, Lafaille JJ, Cua DJ, Littman DR. The orphan nuclear receptor RORgammat directs the differentiation program of proinflammatory IL-17+ T helper cells. Cell. 2006; 126:1121-1133. 